\title{
Resource partitioning revisited: evidence from Italian television broadcasting
}

\author{
Samira Reis*, Giacomo Negro**, ${ }^{*}$, Olav Sorenson ${ }^{\dagger}$, Fabrizio Perretti ${ }^{\star}$ and \\ Alessandro Lomi ${ }^{\S}$
}

The theory of resource partitioning proposes that competition among generalists in the center of a market can trigger a process of resource release that engenders a proliferation of specialist producers outside the center. Previous research has generally examined the relationship between this proliferation and market concentration-a correlate of competitive intensity in the center of the market. In this paper, we extend the theory by arguing that resource release also occurs as the degree of competitive overlap among producers in the center intensifies, even when concentration or other structural features do not vary; we expand its implications by demonstrating that increased competitive overlap in the market center can enhance the viability of producers positioned near the center more than those in the periphery; and we enrich and complete it by specifying the additional assumptions needed to extend the theory of resource partitioning to entry processes. Consistent with our expectations, an empirical examination of the Italian broadcast television industry, from 1992 to 2003, finds that the failure rates of both near-center and peripheral stations decline with greater competitive overlap in the programming of the national broadcasters, with the failure rates of the near-center stations falling more than those of peripheral stations. Greater

\footnotetext{
${ }^{*}$ Samira Reis, Universidad Carlos III de Madrid, Department of Business Administration, C./Madrid 126, 28903 Getafe (Madrid), Spain. e-mail: samira.dias@uc3m.es

${ }^{*}$ Giacomo Negro, Goizueta Business School, Emory University, 1300 Clifton Road NE, Atlanta, GA 30322, USA. e-mail: giacomo_negro@bus.emory.edu

†Olav Sorenson, Yale School of Management, 135 Prospect Street, New Haven, CT 06520, USA. e-mail: olav.sorenson@yale.edu

*Fabrizio Perretti, Bocconi University, Management Department, Via Rontgen 1, 20136 Milano, Italy. e-mail: fabrizio.perretti@unibocconi.it

${ }^{\S}$ Alessandro Lomi, University of Lugano, Faculty of Economics, Via Giuseppe Buffi 13, 6904 Lugano, Switzerland. e-mail: alessandro.lomi@usi.ch

${ }^{\top}$ Main author for correspondence.
} 
competitive overlap similarly stimulates the entry of near-center stations more than peripheral ones.

JEL classification: L25, L82, Z13.

\section{Introduction}

Researchers have found it useful to think of markets as internally differentiated social structures, where some organizations seek to appeal broadly to audiences distributed across a wide variety of social positions, whereas others target the tastes of a more limited range of preferences. The theory of resource partitioning, forwarded by Carroll (1985), provides a systematic description of one process that can produce and maintain this differentiation. In its original formulation, the theory predicted that, under competitive conditions characterized by economies of scale and heterogeneous consumer preferences, a process of resource release would lead concentration among producers that appeal broadly (generalists) to enhance the life chances of those that appeal more narrowly (specialists).

Early support for the theory came from populations of newspapers in the United States (Carroll, 1985). Since then, empirical evidence for resource partitioning has accumulated across a wide range of organizational populations (for a review see Carroll et al., 2002). More recent research has even extended its application beyond businesses-for example, to the study of social movements (Soule and King, 2008). Understanding of the theory has deepened as its application has broadened. Sustained empirical research on the U.S. microbrewery movement has brought to light important details only hinted at in the original formulation (Carroll and Swaminathan, 2000). Formal reconstructions of the theoretical terms underlying resource partitioning meanwhile have extended our understanding of the relationships between the characteristics of the resource space, the locations of producers in it, and partitioning processes (Peli and Noteboom, 1999; Vermeulen and Bruggeman, 2001; Hannan et al., 2007; Kovacs and Carroll, 2010).

Within this context, the aims of this article are threefold: (i) extending the scope of resource partitioning theory, (ii) expanding its range of predictions, and (iii) offering empirical evidence in support of its recent formal reconstructions. First, the theory of resource partitioning posits that specialist subpopulations proliferate through the mechanism of resource release. As generalist producers attempt to expand, they simultaneously move into more intense competition with other generalist producers and withdraw from less central regions of the resource space, releasing these resources for smaller, more specialized producers. But extant empirical models of resource partitioning have relied on increases in market concentration as the observable instigator of this process. Accordingly, settings where concentration does not vary have been considered inert with respect to resource partitioning. We 
propose another path for the activation of resource release: competitive overlap. Even though the moves of generalists may not result in increasing concentration, strategic convergence can still lead to resource release and therefore promote partitioning processes. By introducing another activation mechanism, we extend the scope of the theory to encompass populations and periods where concentration does not vary.

Second, following recent reformulations of resource partitioning, we examine how its dynamics vary across two kinds of specialist producers-those positioned near the market center versus those in the periphery. Although the original formulation distinguished only between generalist and specialist producers, in the process of formalizing the theory and verifying its underlying assumptions, Hannan et al. (2007) found it necessary to redefine generalists as "center" producers and to refine the notion of specialists as being comprised of two somewhat-distinct sub-forms: "near-center" and "peripheral" producers. Following this distinction, we posit that, when the competitive overlap of center producers increases-that is, when one encroaches on the offerings of another-then some positions near the boundary of the center become underserved, increasing the viability of producers outside of the center. Producers whose niches intersect the center and who can engage the resources available there-near-center producers-should benefit more from this release than those in the periphery.

Third, the conditions necessary for resource partitioning to operate on entry processes remain somewhat underspecified. When resource partitioning occurs, the population of near-center and peripheral producers might grow through either of two processes: On the one hand, even if entry rates remain constant, these producers may grow in number as a result of a reduction in their failure rates. On the other hand, potential entrepreneurs and the managers of firms outside the industry might spot the opportunities opened by the retreat of the center producers and rush into the market. The number of near-center and peripheral producers could then increase even without an improvement in their survival rates. We argue that the partitioning of the resource space through entry processes requires that entrepreneurs or external constituents observe and understand the competitive processes unfolding in the center of the market. Such conditions hold when near-center firms-mid-sized producers occupying niches overlapping those of the center producers-exist to interpret and respond to the center producers' actions.

Empirically, we analyzed the population dynamics of the Italian television broadcasting industry from 1992 to 2003 . This setting offers at least three advantages in studying partitioning processes. First, differing geographic scopes divide the population into three distinct sets of organizations that fit well with the theoretical assumptions of resource partitioning: the six national broadcasters (center), dozens of multi-local consortia (near-center), and hundreds of local broadcasters (periphery). Second, detailed information on the programming of the center producers (national broadcasters) allows us to measure their competitive behavior directly, through changes in the overlaps in their offerings (rather than relying on 
concentration as a proxy for this behavior). Third, the number and the market concentration of the national broadcasters remained relatively stable over the period that we study. The intensity of their competitive interaction and their coverage of the resource space nonetheless varied substantially. As a result, we can isolate resource release due to changes in competitive overlap from other potential mechanisms that might account for growth in the populations of near-center and peripheral producers.

Our results strongly support resource release, the mechanism initially forwarded by Carroll (1985), as the driver of partitioning processes: When the competitive overlap among national broadcasters increases, the failure rates of near-center and peripheral stations decline. Our results also reveal the value of further differentiation of the market space: Stations that belong to multi-local consortia-those located nearer to the center of the market-showed far greater sensitivity to the increasing similarity of the national broadcasters' offerings. Finally, our results suggest that entry into the subpopulation of multi-local consortia members rises as the competitive overlap between the national broadcasters increases.

\section{Resource partitioning}

In its original formulation, the theory of resource partitioning included two sets of assumptions. A first set concerned the behavior of consumers/clients, seen as heterogeneous in their preferences and choices. A second set governed the behavior of producers, believed to benefit from scale, but also to be constrained in their ability to engage diverse sets of consumers. More recent reformulations largely maintain these core assumptions: Hannan et al. (2007), for example, build the theory from assumptions of scale advantages, of the existence of a market center, of a distinction between center and non-center positions, and of a set of producers whose niches span these segments. Let us begin by reviewing these core assumptions.

Assumption 1: Market center. Resource partitioning first assumes that consumers have heterogeneous preferences and that the distribution of those preferences has a center (Boone et al., 2002, Hannan et al., 2007). By center, we mean that a small number (or range) of positions attract more consumers than others. In American newspapers, national and international news in English account for the core interests of the majority of readers. In television broadcasting, news, major live sporting events, drama series and sit-coms attract the largest viewership and constitute the center of the preference space. By contrast, programming in a foreign language or dialect, or the coverage of small, local events, would represent tastes outside the center that appeal only to small audience segments.

Assumption 2: Center, near-center and peripheral organizations. Partitioning also assumes that one can sort producers into three groups according to their roles in this consumer space (Hannan et al., 2007). Center producers focus on offering products 
and services that appeal to the center of the distribution of preferences. Near-center and peripheral producers, by contrast, offer goods that appeal most to consumers outside of the center. Near-center and peripheral producers are nonetheless distinct. Although near-center producers appeal primarily to consumers outside of the center, consumers in the center would still consider their products and services in the absence of more attractive alternatives from center producers. Near-center producers therefore compete with center producers for customers, but they themselves do not focus on the central consumer. A near-center television station, for example, could provide coverage of a national youth soccer championship. It potentially appeals to a broad audience, but primarily if it does not compete against professional sporting events. Peripheral producers, by contrast, do not compete against center producers as they offer products and services that appeal only to consumers outside the center of the market. A peripheral television station, for example, might broadcast an old movie with an expired copyright.

Assumption 3: Crowding. The theory also assumes that the center and that the market as a whole contain only a finite amount of resources (e.g., consumers), and that all producers require some minimal amount of resources to survive. As a result, producers within each of these segments compete (diffusely) with one another for scarce resources: Center producers compete with other center producers. Peripheral producers compete mainly with other peripheral producers. And near-center producers compete with other near-center producers, but also with center and peripheral producers (because they straddle these two segments of the market).

Assumption 4: Scale advantages. Resource partitioning further assumes the presence of scale advantages (Carroll, 1985). These advantages can arise from production; for example, much of the cost of a newspaper stems from research and writing while the marginal cost of an additional copy includes only printing and distribution. Television has even stronger production-related economies of scale. Because broadcasters incur no incremental costs when an additional person receives the signal, television involves only fixed costs with respect to the number of viewers (Owen and Wildman, 1992). But scale advantages can also arise from factors not directly related to production; for example, the major advantage of the macro-brewers, such as Budweiser and Heineken, stems from their massive advertising.

These scale advantages generate increasing returns, particularly for the producers targeting the center. As the mass of consumers in the center affords scale advantages, center producers can increase the quality or reduce the price of their offerings to attract consumers with tastes similar to, though somewhat distinct from, those they already serve. Newspapers add pages to cover additional topics of interest. Television stations improve the quality of their programming and acquire rights to popular offerings, such as films and major sporting events. Initial differences in customer bases thus grow as larger producers capture consumers from smaller ones with similar offerings. Growth, in turn, sustains even greater scale advantages. If left unconstrained, in the long run, this process would produce industries containing 
no more than a few, large center producers (or perhaps just one monopolist). The next assumption, however, places limits on this process.

Assumption 5: Limits to scope. Finally, resource partitioning places limits on scale-based growth by assuming restrictions on the range of preferences to which any one producer can appeal (Peli and Nooteboom, 1999). This assumption has largely been incorporated through the principle of allocation-a tradeoff between niche width and strength of appeal (Hannan et al., 2007). Early formulations assumed that technical constraints accounted for these limits. For example, in Carroll's (1985) original study of newspapers, adding pages to appeal to non-Englishspeaking immigrants might help a newspaper to reach a larger share of residents in a region, but the cost of printing and distributing those extra pages to everyone would often exceed the revenue from the incremental readers.

More recent revisions have noted that social factors can also effectively limit scope (Carroll et al., 2002). For example, Carroll and Swaminathan (2000) argued that being engaged in mass production effectively precludes the macro-brewers, such as Coors, from appealing to the consumers of microbrews, who value small-batch production. Because producers that attempt to engage too many social positions end up having little appeal to any particular consumer, they find themselves disadvantaged relative to producers that tailor their offerings to a narrower audience. If microbrewers (near-center and peripheral producers) did not exist, consumers in the periphery might consume the beers of the macro-brewers. But the presence of these microbreweries effectively circumscribes the ability of the macro-brewers to appeal to all audiences.

In television, organizations face a time constraint. Broadcasters can only air one program at a time and therefore cannot expand their appeal through simultaneous offerings (unless they expand the number of channels). Bandwidth, therefore, places a strict limit on the scope of any one organization.

From these assumptions emerges a picture in which center producers compete with each other, as well as with the near-center producers, to capture ever-larger portions of the market. The surviving center producers become large, offering products and services with broad appeal. Peripheral producers meanwhile serve segments of customers in the long tail of the distribution of tastes.

Figure 1 illustrates this process graphically. The squares in the figure denote the total resources available to producers in each environment - though depicted here in two dimensions, in reality these spaces have high dimensionality incorporating a number of consumer, employee and investor preferences. The circular areas represent the resources captured by individual producers, with the largest ovals depicting the center producers and the smaller and dashed ones the near-center producers. In the case of the peripheral producers, these resource bases become quite small and hence they appear as points.

Panel A depicts an intermediate stage of development in some industry, with two center producers, four near-center producers and a number of small peripheral 


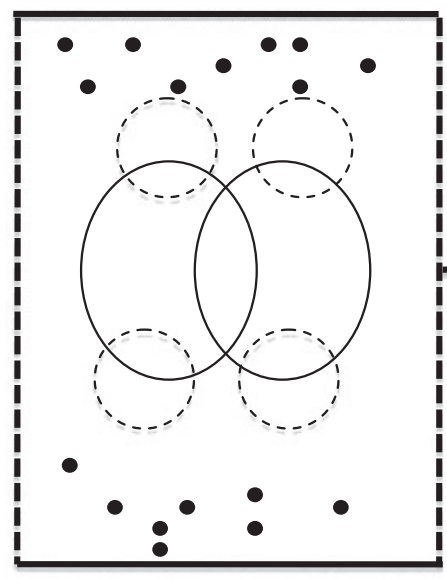

Panel A

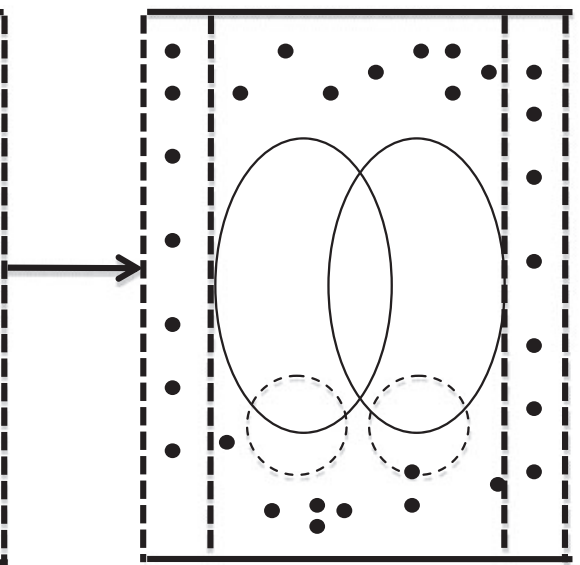

Panel B

Figure 1 Consolidation of producers in the market center.

producers. Panel B then illustrates the changes typically predicted by resource partitioning. The center producers expand into the space occupied by two of the near-center producers. This expansion drives out these near-center producers; they cannot compete with the scale advantages enjoyed by the larger center producers. The center producers can therefore more effectively appeal to audiences near to the center of the taste distribution. The demise of near-center producers, in turn, engenders the proliferation of producers in the periphery. Spaces-in the diagram, at the edges-emerge in which peripheral producers can now operate successfully. Hence, the number of producers in the periphery actually grows in response to industry consolidation.

Past empirical research has connected this process of strategic convergence to consolidation and therefore to the increasing concentration of the market. While convergence often leads to consolidation, we propose that analogous organizational dynamics can initiate resource release even in cases when concentration does not change meaningfully.

Consider Figure 2. Moving from panel C to panel D in this figure, the positions of the producers in the center shift as they compete more intensely with one another, as one producer encroaches on the position of a close rival. This shift does not lead to consolidation; the number and size of the center-producers do not vary. But strategic convergence still releases resources. As the center producers focus on competing for the same consumers, they fail to engage fully all of the social positions formerly served and therefore neglect at least some positions near the edge of the market center. Doing so opens opportunities for near-center producers. Resource release and partitioning therefore can occur even in the absence of changes in market concentration. Although the dynamics portrayed in Figure 2 can (and probably do) occur in 


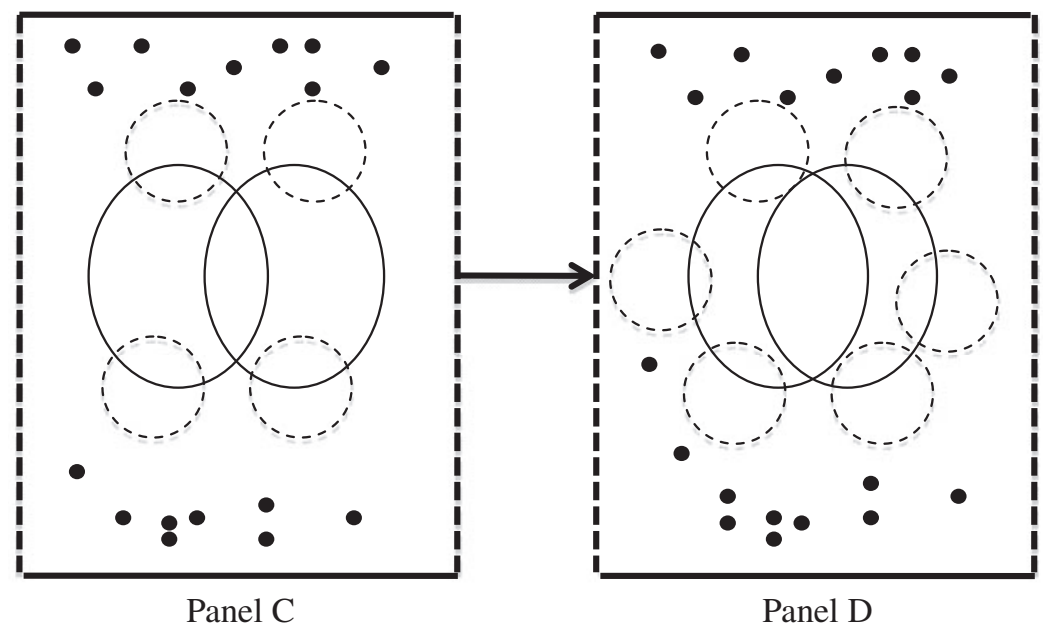

Figure 2 Convergence of producers in the market center.

conjunction with consolidation and increasing concentration (Figure 1), we can more easily isolate and observe them in cases in which the number of center-producers and their aggregate concentration remains relatively constant.

\subsection{Implications for exit}

From these assumptions one can derive predictions for organizational mortality: Increasing overlap among the center producers in an industry releases resources for near-center producers, thereby raising the probability that near-center producers capture these resources and lower their likelihood of failure. If near-center producers shift their offerings toward the center to capture these resources, then these shifts can create a kind of vacancy chain-releasing resources in the periphery and improving the survival rates of peripheral producers. Because peripheral producers benefit only indirectly, however, as near-center producers shift their positions, they should experience more muted effects. Hence, the theory suggests:

Hypothesis 1: The failure rates of near-center and peripheral producers decline with increasing overlap in the offerings of center producers.

Hypothesis 2: The failure rate of near-center producers declines more than the failure rate of peripheral producers with increasing overlap in the offerings of center producers.

\subsection{Implications for entry}

Linking competitive overlap among center producers to the entry rates of near-center and peripheral producers requires additional (behavioral) assumptions. If one adopts 
the simplest assumption-that entrepreneurs enter at random positions in the resource space-then one would expect no relationship between competitive overlap and entry (though partitioning processes could still operate through selection). Establishing a connection between competitive overlap and entry requires either: (i) that potential entrants accurately observe the opportunities opened by the convergence of the producers in the center or (ii) that resource providers-financiers, suppliers and skilled employees-accurately observe these opportunities and refuse to support entry under unfavorable conditions.

These assumptions act as substitutes in connecting shifts in competitive overlap to entry because entry itself comprises two processes: attempts at entry and resource mobilization. Potential entrants, be they entrepreneurs or existing producers in other industries, decide first whether they have an interest in engaging a social position. They must then acquire the resources - the capital and the employees - to begin operations. For existing producers, this second stage may not present much of a barrier, but it does for many would-be entrepreneurs (Sørensen and Sorenson, 2003). Hence, an increase either in the number attempting entry or in the rate at which these attempts transition to production could raise the entry rate.

But do potential entrants (or resource holders) accurately assess the competitive moves of center producers? Potential entrants are almost certainly aware of the large producers that occupy center positions. They may even notice when these firms abandon a niche, if only because they perceive the absence of a product or service once provided. If they do, and if that observation leads to the perception of an attractive opportunity, then increasing competitive overlap among the center producers should encourage entry.

But one could also imagine that potential entrants do not notice the actions of the center producers or consider their strategic shifts irrelevant. Prior research suggests that entrepreneurs and managers tend to form competitive sets too narrowly, only considering as rivals those most similar (Porac and Thomas, 1994; Camerer and Lovallo, 1999). Given the differences in the positions that they target, entrepreneurs may feel as if they have little in common with center producers. If potential entrants ignore or consider irrelevant the activities of these center organizations, then the degree of competitive overlap among the center producers might have little bearing on entry.

One could even imagine that the release of resources by center producers might deter entry if would-be entrants interpret this signal incorrectly. Sørensen and Sorenson (2003), for example, found that attempts at entry in the U.S. television industry rose with recent entrepreneurial entry, despite the fact that this entry intensified competition and therefore reduced the attractiveness of the industry. Similarly, potential entrants might generally interpret the abandonment of positions by the center firms as a signal of the declining attractiveness of those positions rather than as a consequence of the center firms focusing on one another. 
The empirical literature has posited a positive relationship between increasing concentration among the generalists and the entry rate of specialists (Freeman and Lomi, 1994; Wade, 1995; Carroll and Swaminathan, 2000; Mezias and Mezias, 2000; Swaminathan, 2001). One can therefore infer that the (implicit) assumptions have been: (i) that would-be entrepreneurs monitor the activities of the center producers; (ii) that they correctly interpret the fact that increased overlap increases the similarity of offerings, opening opportunities for entry; and (iii) that they act on these observations. Conditional on these assumptions, one would expect a positive relationship between the degree of overlap in the center and entrepreneurial entry.

Hypothesis 3: The entry rates of near-center and peripheral producers increase with the degree of overlap in the offerings of center producers.

The distinction between near-center and peripheral producers offers further insight into these behavioral assumptions. Recall that the niches of near-center producers overlap with the center whereas those of the peripheral producers do not. If one believes that would-be entrepreneurs evaluate the expected attractiveness of the niches that they consider entering, then this assessment would lead those considering entry in the near-center to monitor and evaluate the activities of their most relevant rivals, the center producers. As a result, one would expect entry rates into the near-center to depend far more directly on the offerings of the center producers.

Hypothesis 4: The entry rate of near-center producers increases more than that of peripheral producers with increasing overlap in the offerings of center producers.

\section{Italian television broadcasting}

The Italian television broadcasting industry, from 1992 to 2003, served as the setting for testing our hypotheses. During the study period, Italian viewers primarily consumed free terrestrial television, with the typical viewer having access to six national channels and several local channels (between 10 and 30 depending on the location). ${ }^{1}$ Pay television, by contrast, has only recently begun to play a role in Italy. By the end of our study period, cable and satellite, combined, had still reached less than ten percent of Italian households, and pay television had a penetration of less than five percent. In this respect, Italian television differed markedly from the United States, where cable and satellite had already diffused widely.

We approached the study with a multi-method design, first interviewing the owners and managers of several stations and then gathering a database that incorporated information both on the programming of the national broadcasters and on

\footnotetext{
${ }^{1}$ Beginning in 2001, Telecom Italia began to build another national broadcaster, La7, but this channel had yet to reach significant audience share by the end of our observation window.
} 
the entry and exit of broadcasting organizations. ${ }^{2}$ Before moving into our quantitative analysis, let us first review the fit of our setting to the assumptions outlined earlier.

We have already noted that broadcast television exhibits strong scale advantages (Owen and Wildman, 1992). In programming, broadcasters incur substantial fixed costs but adding viewers imposes no incremental costs. In Italian television, the national channels also benefit from their ability to spread the costs of their own productions across a larger base of viewers. We have also already explained that broadcasters face binding constraints on their scope, or breadth of appeal. In television, channels can only broadcast one show at a time. Bandwidth, therefore, places a severe limit on the scope of any one station.

Italian television also had a distribution of preferences with a center: The median Italian viewer preferred feature films from Hollywood, variety shows, and news programs (Wagstaff, 2001). Together these offerings accounted for more than $93 \%$ of the minutes of television watched in Italy during our study period.

The industry sorts quite well into center, near-center and peripheral producers. The national channels targeted the center, allocating $70 \%$ of their prime-time minutes ( 8 to $11 \mathrm{pm}$ ) to Hollywood blockbusters, variety shows and news programs. Two organizations owned these channels: the state-owned RAI, which served as an umbrella for three channels (Rai 1, Rai 2, Rai 3) funded by license fees (55\% of total revenues) and advertising revenues (45\% of total revenues), and the privately-owned Mediaset, composed of three commercial channels (Canale 5, Retequattro and Italia 1) funded only by advertising revenues. Despite their common ownership, each of these channels operated independently, with its own management, budget and resources. Together, they captured between $88 \%$ and $91 \%$ of television viewing in each year of our study.

Local broadcasters began to emerge in Italy in the late 1970s (Barca, 2007). These organizations operated in the periphery, focusing on highly local programming, in large part because they could not afford to program films or to produce variety shows or news programs with non-local coverage. One local station owner we interviewed, for example, programmed for the Slovenian ethnic minority in the city of Gorizia. Another concentrated on agriculture, food and environmental issues in and around the southern city of Brindisi. During our interview, the owner of Imperia TV (another peripheral firm located in the Northwest close to the French border) described a typical primetime lineup:

Only local things. We had the historical parade of San Benedetto, then a special on olive oil production, and then coverage of the sports championships for disabled athletes organized in Imperia. In general, during prime time we have one-hour program slots that typically focus on local issues and events. We have a

\footnotetext{
${ }^{2}$ The subsequent quotes represent our own translations of interviews conducted in 2006 and 2007.
} 
musical program because our viewers from the inland region like music. We do not broadcast films.

Someplace between these two extremes were the organizations that belonged to multi-local consortia. Although these organizations each operated a single, local channel and remained responsible for its programming, membership in a consortia allowed them to share certain operational and programming costs. Pooling audiences, moreover, allowed them to program older films and to produce regional and national news, though they still could not afford to purchase rights to the latest movies or to produce popular variety shows (offerings in the center of the consumer preference distribution). Telenova and the other stations affiliated with the Cinquestelle consortium, for example, broadcast Italian-language movies and Hollywood productions that had completed their commercial runs with the national channels. They also produced second-run variety shows. For instance, after losing his talk show on the RAI and then on Mediaset, Gianfranco Funari (a very popular anchorman) began to host evening talk shows for the Odeon consortium.

Based on these distinctions, we considered the national broadcasters to occupy the market center, the stations affiliated with multi-local consortia to operate in the near-center and the independent local operators-each of whom operated a single channel-to engage the periphery. Consistent with these distinctions, the broadcasters also attracted different advertisers. National and international companies purchased time from the national stations, whereas local channels received advertising revenue largely from local organizations. Multi-local consortia sold to a combination of local and larger, regional companies.

\subsection{Measures and estimation}

Our quantitative data combined information from several sources. The Guida all' Emittenza (GAE), a directory of all local television stations in Italy, served as our primarily source of information on near-center and peripheral producers. GAE garners this information from public records generated by the regulation of broadcast television. Mediaset SpA provided us with detailed information on the programming of the six national broadcasters. We cross-checked the data and constructed controls from information provided by the Italian Department of Communication and two reference sources, the Rapporto sull'Economia della Cultura in Italia (Bodo and Spada, 2004) and Il Mercato degli Audiovisivi in Italia (ISTAT, 1999). The sample analyzed includes information on all television stations operating in the Italian peninsula, a total of 858 stations. $^{3}$

\footnotetext{
${ }^{3}$ We excluded the islands of Sardinia and Sicily from the analyses.
} 


\subsubsection{Dependent variable: exit}

The broadcasting organization serves as our unit of analysis for the exit rate models. We considered an organization to have exited when it did not appear in the directory for the subsequent year. Organizations can exit the industry in many different ways, through disbanding, by being acquired, or by moving into another line of business. As we could not identify the mode of exit, our analyses estimated the aggregate transition rates for all forms of exit.

We initially estimated these transition rates using a piece-wise exponential model. Further inspection of the data, however, revealed no significant patterns of duration dependence. The reported models therefore simplify to an exponential model with a constant hazard rate. The exit rate models also included a dummy variable for left-truncation (i.e. organizations already operating in 1992). Table 1 reports descriptive statistics for the variables used in the exit rate analysis.

\subsubsection{Dependent variable: entry}

Our second dependent variable counts the number of entries (in a particular subpopulation) in a region in a given year. We defined an entry event as occurring in the first year in which an organization broadcasts. Following a well-established analytical strategy, we estimated event-count models where the regional organizational subpopulation itself serves as the unit at risk of events (Carroll and Hannan, 2000). We used a negative binomial specification — which allows for over-dispersion due to contagion or other unobserved factors - with standard errors clustered on region-years to allow for correlated patterns of entry across near-center and peripheral organizations in the same regions and years. ${ }^{4}$ Table 2 reports descriptive statistics for the variables used in the entry rate analysis.

\subsubsection{Independent variables}

Our primary explanatory variable of interest is the degree of competitive overlap among the six national television channels, a variable that captures the proportion of the time that the national broadcasters simultaneously aired the same genre during primetime $(8$ to $11 \mathrm{pm}) .^{5}$

We generated this measure in two steps using audience share data from Auditel (an organization that measures the share of television audiences in Italy). First, we constructed dyadic overlap measures. For each of the 15 possible pairings of stations $\left[=\left(N^{2}-N\right) / 2\right]$, in each 6-min interval of primetime across the 11 years, we

\footnotetext{
${ }^{4}$ Because GAE did not publish its directory every year, we included an exposure term for observations covering two years of entry rather than one.

${ }^{5}$ The program genres used to measure competitive overlap come from a classification developed by Auditel: Cartoons, Cultural Programs, Light Entertainment, Made-for-Television Films, Movies, Music, News, Quiz/Game Shows, Reality Shows, Short Series, Situation Comedies, Soaps, Soft News, Sports, Talk Shows, and Teleshopping.
} 
Table 1 Descriptive statistics for exit rate analysis

\begin{tabular}{lrccc}
\hline Variable & Mean & Std. Dev. & Min & Max \\
\hline Censoring & & & & \\
Density of peripheral television stations in region (In) & 0.845 & 0.362 & 0 & 1 \\
Density of near-center television stations in region (In) & 2.612 & 0.711 & 0.693 & 4.745 \\
Regional population (In) & 15.044 & 0.508 & 0 & 3.045 \\
Regulatory change & 0.509 & 0.500 & 0 & 1 \\
Local advertising (In) & 6.340 & 8.155 & 0 & 30.109 \\
Market concentration & 89.755 & 0.658 & 88.68 & 90.8 \\
Competitive overlap & 0.169 & 0.031 & 0.13 & 0.22 \\
Peripheral station & 0.794 & 0.405 & 0 & 1 \\
Transition & 0.054 & 0.225 & 0 & 1 \\
& & & & \\
\hline
\end{tabular}

Table 2 Descriptive statistics for entry rate analysis

\begin{tabular}{lrccc}
\hline Variable & Mean & Std. Dev. & Min & Max \\
\hline Entry & 1.210 & 2.621 & 0 & 16 \\
Density of peripheral television stations in region (In) & 2.971 & 0.954 & 0.69 & 4.74 \\
Density of near-center television stations in region (In) & 1.809 & 0.670 & 0.00 & 2.89 \\
Regional population (In) & 14.395 & 1.089 & 11.66 & 16.02 \\
Regulatory change & 0.571 & 0.496 & 0 & 1 \\
Local advertising (In) & 9.289 & 7.571 & -9.21 & 12.74 \\
Market concentration & 88.956 & 1.696 & 85.57 & 90.70 \\
Competitive overlap & 0.157 & 0.026 & 0.13 & 0.22 \\
& & & & \\
\hline
\end{tabular}

determined whether the two stations programmed the same genre, coding overlap as a one. ${ }^{6}$ We then averaged the values of those dyadic 6-min intervals for each year to derive the proportion of the time that stations overlapped in their programming. Theoretically, competitive overlap could range from zero, if the national channels never aired programs of the same genre at the same time, to one, if all national channels always programmed similar content in the same time slots. Figure 3 graphs the average level of competitive overlap over the study period.

\footnotetext{
${ }^{6}$ We used 6-min intervals to accommodate the fact that programs can begin and end at virtually any time in Italian television. Unlike the United States, the national stations do not necessarily program in half-hour slots.
} 


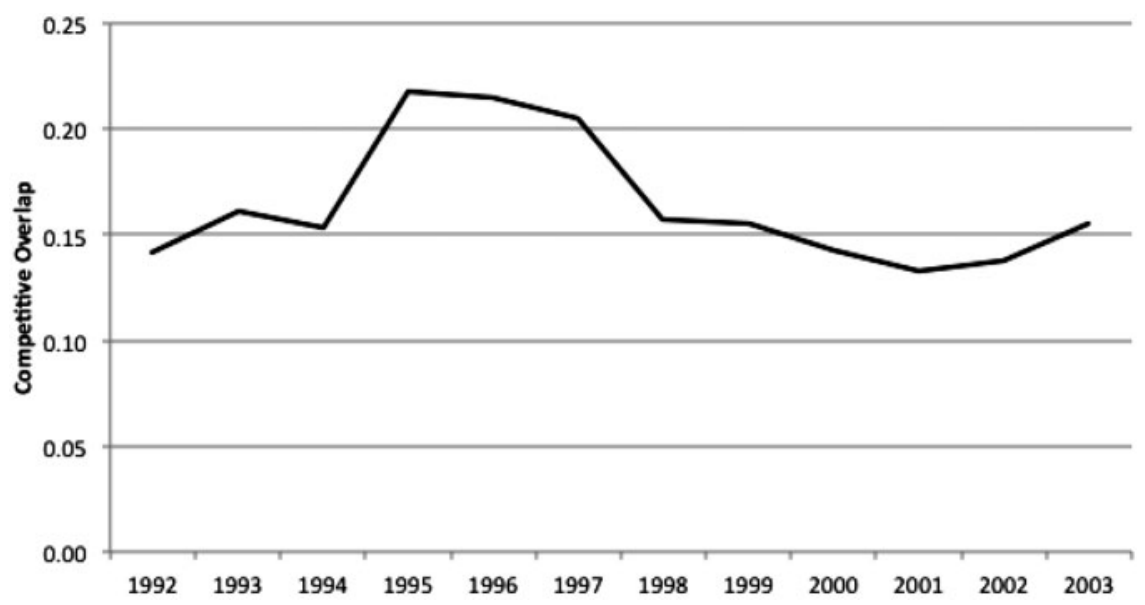

Figure 3 Evolution of competitive overlap among national TV channels, 1992-2003.

In the exit rate models, we lagged competitive overlap by 1 year, and in the entry rate models, we lagged it by 2 years. The process of moving from the decision to attempt to start a station to broadcasting requires roughly 24 months of planning in Italy (Demattè and Perretti, 2002). Since the theory underlying Hypotheses 3 and 4 depends on the decision to attempt entry in response to changes in the competitive overlap of the center organizations and since our data on entry measures the first year of broadcasting (rather than the year of applying for a license), a 2-year lag appeared most appropriate. ${ }^{7}$

As noted above, two organizations, RAI and Mediaset, dominate the Italian television industry, each controlling three terrestrial channels. Although both RAI and Mediaset run their channels as independent profit centers with their own budgets and management, they nevertheless have an incentive - and the potential ability - to coordinate programming across their channels (Demattè and Perretti, 2002). That raises the possibility that our measure might conflate changes in the internal level of coordination with changes in the level of competitive overlap. To assess whether this possibility might influence our estimates, we also calculated competitive overlap including only the cross-organization pairings of channels (Rail-Canale5, Rai1-Italia1, etc.) but not the within-organization pairings (Rai1-Rai2, Canale5-Italia1, etc.). Models 3.3 and 4.3, using this alternate measure, generated results qualitatively identical to those obtained using the measure calculated from all channel pairings.

\footnotetext{
${ }^{7}$ We explored whether other lags would work equally well, but, consistent with our expectations, two-year lags produced the best-fitting entry models.
} 
Given that prior studies of resource partitioning have focused on concentration rather than competitive overlap, we created a control for market concentration. Using information from Auditel, we calculated the aggregate share of the audiences of the six national broadcasters over the course of each year. As research on resource partitioning essentially assumes that concentration proxies for competitive intensity, we used the same lags for concentration as we did for competitive overlap (i.e. one year for the exit models and two years for entry).

To classify stations as center, near-center and peripheral we determined whether an organization operated as a national channel, as a member of a multi-local consortium or as an independent local station. This partition divides broadcasters into three distinct sets in terms not only of geographical scope but also of targeted audience positions. Only the six national channels, operated by RAI and Mediaset, broadcast the latest movies and popular variety shows across Italy. We distinguished between near-center and peripheral producers by focusing on whether the station had an affiliation with a multi-local consortium each year. ${ }^{8}$ These multi-local consortia vary in scope; the largest, such as Italia 9 Network, with 44 members, and Corallo, with 28 members, have near-national coverage. But many smaller groups, such as Cinquestelle, Europa 7, and Supersix cover only two or three regions. As discussed above, these consortia nevertheless differ qualitatively from the local stations because they share programming across their stations, allowing them to gain (limited) economies of scale and to broadcast offerings closer to the center of audience preferencesolder movies, some variety shows and regional news. Local stations only broadcast programs like news or sporting events with a local content.

\subsubsection{Control variables}

Our analyses also included several variables to control for regional- and nationallevel factors that might influence entry and exit rates. First, we included measures of the availability of resources. One variable, regional population, counts the number of people in the region, the set of potential viewers. Another, local advertising, measures the total amount spent on regional television advertising nationwide (in tens of thousands of Euros). As more money becomes available, advertising can presumably support a larger number of local broadcasters.

Second, we included controls for other more general institutional and competitive processes through density dependence (Carroll and Hannan, 2000). Our study period encompasses pre-peak density years and the data suggest that station density climaxed during the study period in several regions: Calabria, Campania, Lazio, Lombardia, Puglia and Veneto. Accordingly, the models included counts of the

\footnotetext{
${ }^{8}$ We also explored two other measures of position, one based on the structural complexity of the organizations and another based on their sizes. Although these measures only correlated moderately with geographic scope, both produced parallel results to those reported here. It therefore appears that the differences between near-center and peripheral firms involve multiple dimensions.
} 
number of local stations operating in the same region as the focal firm (density of peripheral television stations and density of near-center stations). We measured the densities of peripheral and near-center stations separately to examine whether these subpopulations have different dynamics.

Third, our analyses included a variable to capture the effects of an important regulatory change. In 1997, the law N.249 fixed at 30\% the maximum share of the total industry resources-advertising and license fees-that any broadcaster could receive. At the local level, this law also established limits on ownership concentration and rules for channel allocation to minimize signal interference (Demattè and Perretti, 2002). We included a period variable equal to one on and after 1997, and zero otherwise, to capture the effects of this legislation. Although we explored the importance of other changes in the political and regulatory environment, we found no other significant period effects during our observation window.

Finally, the exit rate models included an indicator variable equal to one if the organization transitioned from near-center to periphery status and vice versa, and zero otherwise. In unreported analyses we did not find significant differences in the effect of the two types of transitions added separately to the models.

\section{Results}

Table 3 reports our exit rate estimates. Beginning with Model 3.1, several results deserve attention. First, the 1997 regulatory change hurt local and multi-local broadcasters. Though the change imposed restrictions on all broadcasters, the smaller stations had less ability to flout its terms and therefore appear to have suffered more from its introduction. Second, failure rates declined with advertising expenditures. As the primary source of revenue, one would expect stations to benefit from an influx of financial resources. Third, exit rates also decreased with the number of people in the region. A larger population presumably supports a greater variety of niches for specialists to exploit. Peripheral density increased failure rates for both near-center and peripheral stations, as one would expect as crowding intensifies outside of the market center. To compare our results with prior research on resource partitioning, the model included a measure of concentration, the aggregate audience share captured by the national broadcasters. Consistent with past studies, concentration had a negative and statistically significant effect on exit rates. Finally, transitions increased exit rates, consistent with the idea that change processes disrupt organizational routines and raise failure rates, at least temporarily, regardless of the content of the change (Barnett and Carroll, 1995).

Model 3.2 introduces competitive overlap to test our first hypothesis. Consistent with Hypothesis 1, the exit rate of local stations declined when national broadcasters became more similar in their offerings. This effect is not only statistically significant but also large. A one-percentage point increase in programming overlap among the 


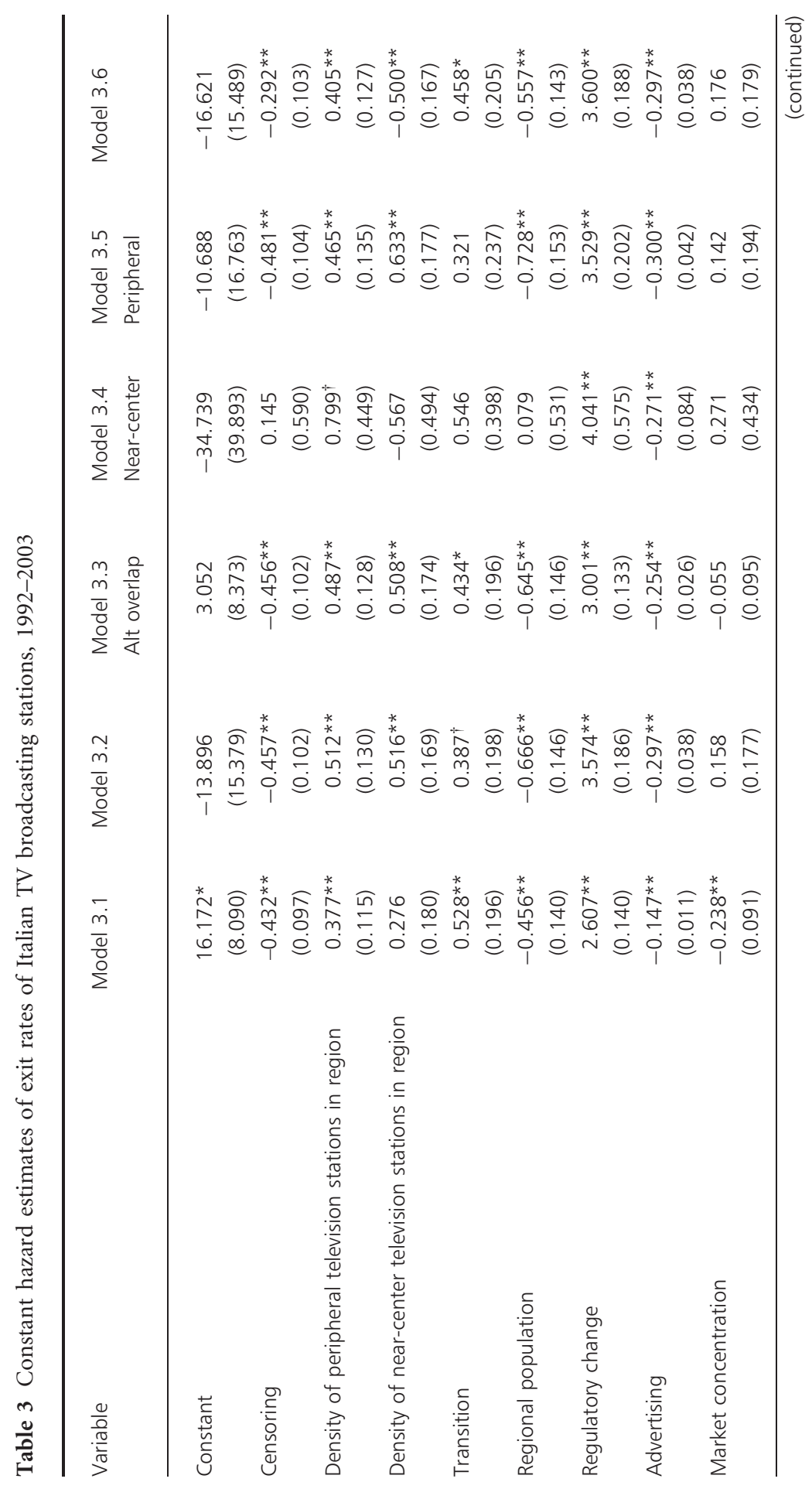




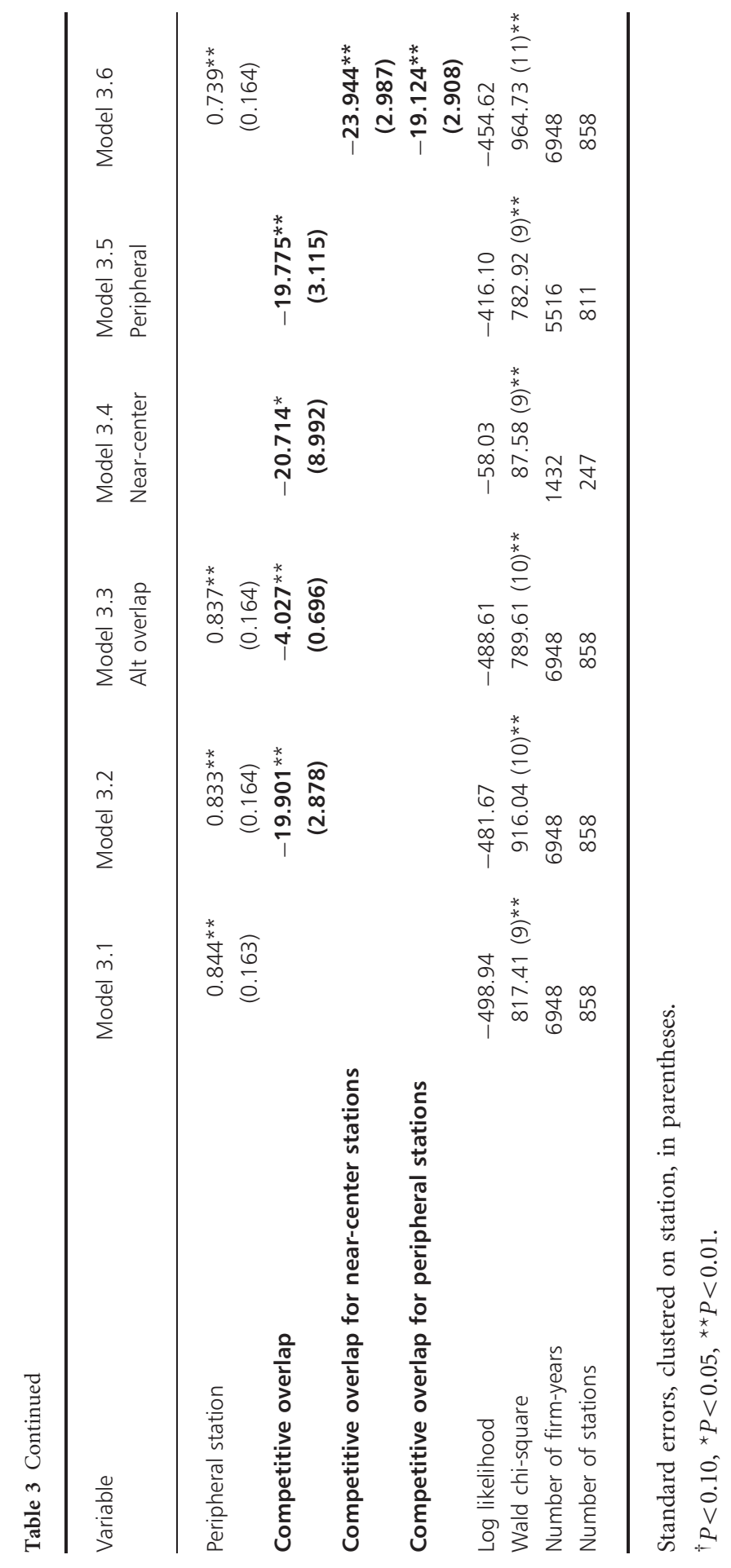


national broadcasters reduces the expected exit rate by roughly $18 \%$. Given that the overlap measure varies by more than eight percentage points over our observation window, the most intense period of overlap implies an $80 \%$ lower failure rate among near-center and peripheral stations than the least intense period. When the national television channels schedule more of the same types of programs in the same time slots, this shift appears to reduce the appeal of the national channels for some viewers, allowing stations that belong to multi-local consortia to engage them. Note that when estimated simultaneously, competitive overlap has both substantial and statistically significant effects while concentration loses its explanatory power.

Model 3.3 re-estimates the previous specification, but replaces the competitive overlap measure calculated across all pairings of channels with the overlap excluding the internal pairings of channels within RAI and within Mediaset. This alternative specification also finds a negative and statistically significant relationship between overlap and exit. Note, however, that the specification with competitive overlap across all national channels provides a better model fit; the Akaike's information criterion (AIC) value is 985.34 for Model 3.2 (vs. 999.22 for Model 3.3). ${ }^{9}$ We therefore focus on models using all channel pairings to measure overlap.

Models 3.4 and 3.5 further examine the distinction between near-center and peripheral stations, estimating the specification from Model 3.2 separately for each of these two subpopulations. Competitive overlap among center firms reduced exit rates for both near-center and peripheral stations. To test our second hypothesisthat near-center and peripheral producers differ in their sensitivities to the actions of the center producers-we estimated a pooled model. In Model 3.6, we split competitive overlap into two variables: One sets the measure equal to the competitive overlap score for the near-center stations and the other sets the measure equal to the competitive overlap score for peripheral stations. Mathematically, this coding is equivalent to including an interaction term between competitive overlap and the type of station. To test the significance of this (implicit) interaction, we calculated a Wald test of the equivalence of the coefficients of competitive overlap for near-center and peripheral stations. Consistent with Hypothesis 2, when competitive overlap among center stations increased, near-center producers experienced a greater decline in exit rates than their peripheral counterparts $\left(\chi^{2}=55.82, P<0.001\right)$. Figure 4 graphs the multiplier rate of producer exit due to competitive overlap for both peripheral and near-center stations over the range of our data.

Although the results appear consistent with our expectations, one might worry that at least two other types of processes could explain them. First, perhaps our measure of competitive overlap captures the changing niche widths of the center producers rather than the intensity of their competitive interactions. To assess this possibility, we used our programming data to calculate niche width using the

\footnotetext{
${ }^{9}$ Smaller values of AIC indicate better fitting models.
} 


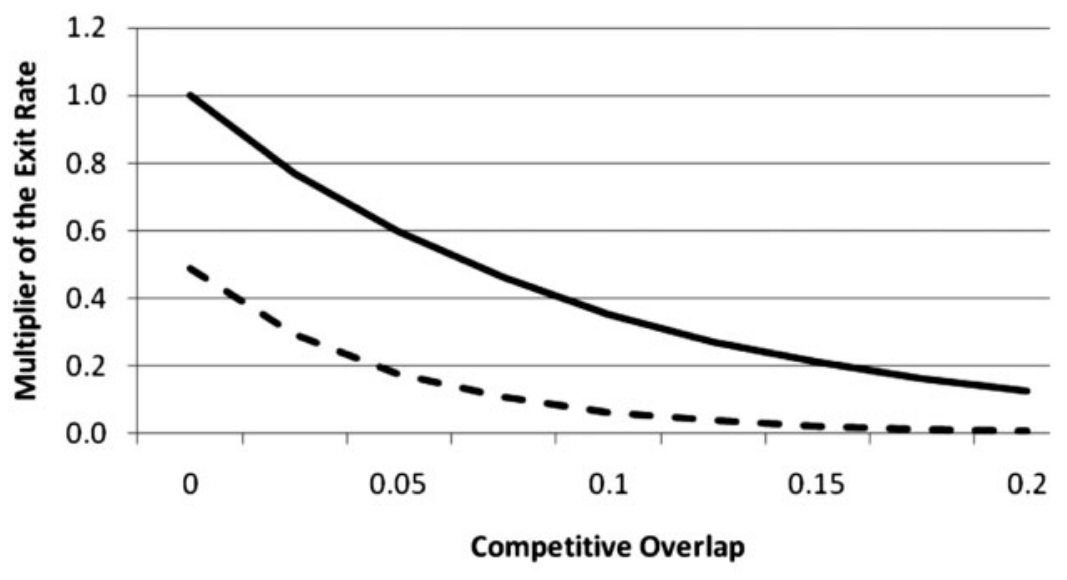

- local stations $\quad$ - $\quad$ multi-local stations

Figure 4 Effect of competitive overlap among national TV channels on the multiplier of exit.

Simpson index of the diversity of programs over genres. Over our window, the niche width of the national channels averaged 0.87 with a range from 0.865 to 0.874 (plus or minus $<0.005 \%$ ). The box plot in Figure 5 depicts graphically the average year-to-year variations in the proportion of programs in the various genres scheduled by the six national channels. Over the study period, the average year-to-year change has been essentially zero and even the range has fluctuated within a narrow band. Hence, the niche width of the center producers does not appear to change even though the level of competitive overlap does, as the national broadcasters shift from programming similar offerings against one another to distinct times.

Second, our models include data on a limited number of time-varying organizational characteristics of the local television stations. One might therefore worry that unobserved heterogeneity at the firm level could bias our estimates. To address this possibility, we estimated our models using firm-level random effects in the form of shared frailty models (Blossfeld and Rohwer, 2002), which capture organizational heterogeneity as a frailty variance parameter (theta) resulting from a multiplicative effect on the hazard function applied to groups of observations-here, different spells within each producer. Not only did our results remain robust to the inclusion of these random effects, but also the effects of shared frailty did not appear statistically different from zero, suggesting that systematic, unobserved, station-specific effects probably do not bias our results. ${ }^{10}$

\footnotetext{
${ }^{10}$ When testing whether an estimated variance component differs from zero (i.e., whether two models differ only with respect to the variance component in question), the distribution of the likelihood-ratio test statistic does not follow the usual chi-squared distribution with one degree of
} 


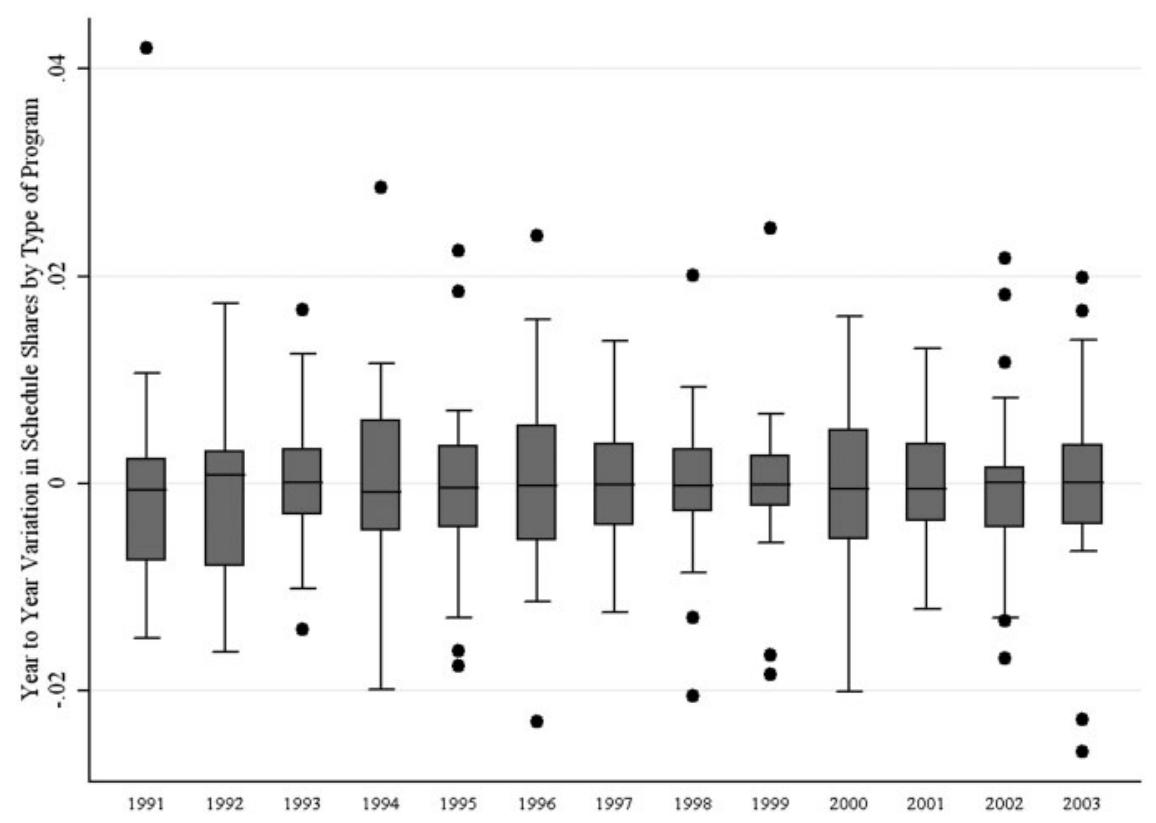

Figure 5 Year-to-year changes in the shares of national programming by program type.

Table 4 reports our models of entry. Model 4.1 includes only the control variables. In this model, we find that the density of peripheral stations increased entry rates whereas near-center density had no significant effect on them. Local advertising reduced entry rates, somewhat unexpectedly. Entries increased more in populous regions and decreased following the introduction of the law regulating the media industry and limiting the concentration of ownership at the local level. When we split the estimates between the two subpopulations of near-center and peripheral stations, we see that the legal change primarily affected the near-center, plausibly suggesting that the limits to consolidation of the market primarily discourage the entry of businesses that would affiliate with a multi-local consortium. Market concentration, which has limited variation, did not affect entry rates significantly.

Model 4.2 adds the competitive overlap measure. Consistent with Hypothesis 3, entry rates rose when competitive overlap increased among the national channels. Though the coefficient has a somewhat higher level of uncertainty surrounding it $(P=0.08)$, the magnitude of the effect seems noteworthy: a one percentage point

freedom but rather a mixture of a chi-squared distribution with zero degrees of freedom and a chi-squared distribution with one degree of freedom. The reported $P$-value of the LR test has also been set to one-half of the probability that a chi-squared with one degree of freedom exceeds the calculated LR test statistic (Self and Liang, 1987). 


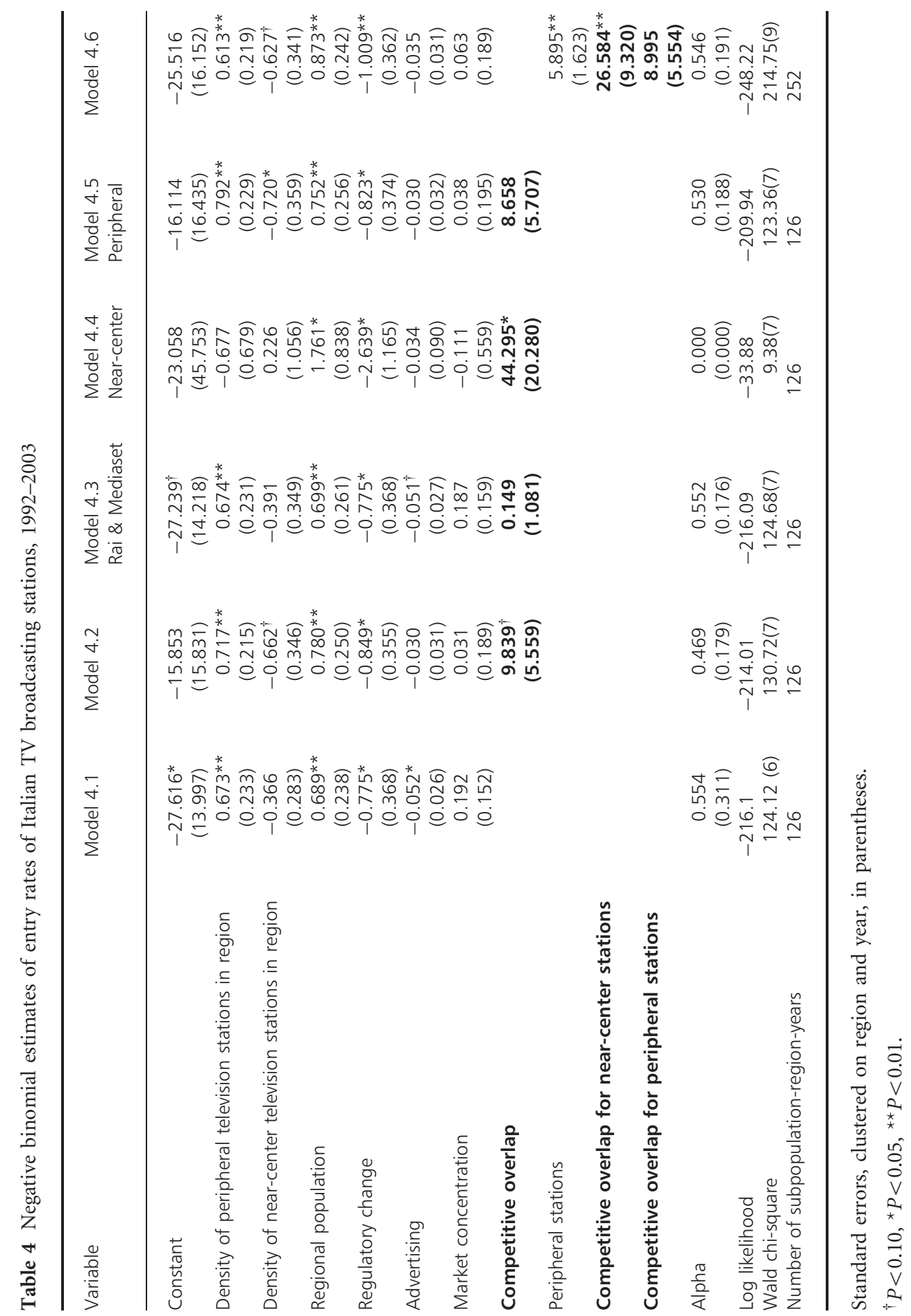


increase in overlap predicted an increase in the entry rate of roughly $10 \%$. Though this effect dropped below conventional levels of statistical significance when we replaced competitive overlap measured across all pairings of channels with overlap excluding pairings of channels within RAI and within Mediaset (Model 4.3), the AIC once again suggests that we should prefer the model using all pairings to the one excluding internal pairings (412.02 vs. 416.18).

We can gain additional insight into the dynamics of entry by turning our attention to the split population models. Models 4.4 and 4.5 report the previous specification for near-center and peripheral stations respectively. Increasing overlap in the programming activities of the national broadcasters had a significant positive effect on the entry of near-center stations but not on the entry in the periphery. Either near-center producers or the resource holders on which they rely appear to observe the strategic moves of center producers and react accordingly; peripheral producers, on the other hand, appeared insensitive to them. To test Hypothesis 4, in Model 4.6 we pooled the estimates for the two sub-populations and split competitive overlap into two variables (in the same manner as in Model 3.6). Consistent with our expectations, we found that competitive overlap had a significantly stronger effect on near-center stations than on peripheral ones.

Our results proved robust to numerous alternative specifications. Lagged entries and exits neither had significant effects themselves nor did they affect our other results. We also found our exit rate models robust to alternative specifications of duration dependence. Our analyses are nonetheless not without shortcomings. One in particular seems relevant: We have a relatively short observation window. Although necessitated by the availability of data on the programming of the national broadcasters, the short panel nonetheless limits the statistical power of our founding rate models and introduces a substantial degree of left-censoring into our exit rate models.

\section{Discussion}

Overall, our results provide empirical support for our revisited model of resource partitioning in the Italian television industry. Exit rates of local and multi-local stations (peripheral and near-center producers) declined when national broadcasters (center producers) overlapped more heavily in their programming, and therefore competed more intensely. Our results also offer strong support for recent extensions of the theory that suggest the need to partition specialists into two subgroups: near-center producers and peripheral producers. Stations in multi-local consortia, which have more similar programming to the national broadcasters, benefited the most from this increasing overlap in the market center. Entry into the industry also increased when the national broadcasters overlapped more heavily, but only in near-center positions. Therefore, as anticipated, entry and exit of near-center producers are more sensitive to differences in competition among the center producers. 
Our results also point to the usefulness of competitive overlap as an additional approach to measuring resource release and to observing partitioning processes. This approach has at least two major advantages. First, it allows the researcher to capture variation in resource release that occurs during periods and in settings where the number and aggregate market share of center firms remain relatively constant. Second, it has the concomitant advantage of allowing the researcher to rule out some of the alternative explanations that could account for a positive correlation between concentration and the viability of specialists. Sutton (1991), for example, proposed a model whereby firms strategically invest in fixed costs, such as production technologies. These investments produce a bi-modal size distribution among firms - some invest, some do not-even though they can manufacture similar products for similar consumers (i.e., occupy the same positions in the resource space). Directly examining the positions of center producers allows us to rule out such alternative explanations that might account for prior results related to concentration. These advantages do not come without cost: In particular, the calculation of competitive overlap imposes far more stringent data requirements on the researcher. But as industry-level data become richer, we see ample room for replicating and extending the study of the effects of competitive overlap to other settings. The American automobile data (Dobrev et al., 2001), for example, include information on the ranges of engine sizes that one could use to assess the degree to which center producers overlapped in their activities. Similarly, datasets with detailed product-level information, such as bicycle (Dowell, 2006), computer workstation (Sorenson, 2000), disk drive (McKendrick, 2001) and laser printer (de Figueiredo and Silverman, 2007) manufacturers, would permit not only measurement of the competitive overlap of generalists, but also an examination of how near-center and peripheral organizations respond to strategic moves in the center.

Interestingly, in our models that included both measures of competitive overlap and of industry concentration, only competitive overlap had a significant effect on either entry or exit. In empirical research to date on resource partitioning, concentration has really only been a proxy for the proportion of the resource space covered by generalists. Competitive overlap, by contrast, measures the underlying competitive behavior of center producers more directly. One might therefore expect it to provide more accurate predictions of the effects of this behavior. Our setting, however, also tips the playing field in favor of this new measure as we observe little variation in concentration. A more interesting comparison of the relative explanatory power of these alternative-and likely complementary-measures would be an industry that has experienced periods both of consolidation and of strategic convergence.

Although our focus has been on extending partitioning theory to situations and time scales where market structure remains relatively stable, our development of this theory has nevertheless also brought attention to behavioral assumptions implicit in the broader research program on resource partitioning, particularly with respect to 
the predictions for entry rates. How one would expect competition among center producers to affect near-center and peripheral producers depends crucially on what one believes about the abilities of potential entrants (or their resource providers) to assess accurately the opportunities opened by contraction in the center of the market.

The insensitivity of the peripheral producers to changing overlap in the center that we found in our estimates corresponds quite closely to what one would have expected on the basis of our qualitative interviews. Local station owners told us that they considered the activities of national broadcasters irrelevant. When asked their thoughts, we received answers like: "I pay no attention," and "I just don't take them into account." The owner of Imperia TV (a peripheral station), related the issue most clearly, telling us that the national broadcasters did not matter to him because: "We are not competing for the same programs; we don't compete for films, series and so on. We are interested in local content." Indeed, peripheral entrepreneurs often reacted vehemently to the idea that they compete with the national broadcasters. For example, Mario Scotto, of Puglia TV, responded:

It is impossible for local TV stations to find a niche in the presence of national channels. You think, they broadcast films from three years ago, and I decide to broadcast a film by Totó [an old classic of Italian comedy], a black and white film because I cannot afford to broadcast color films ... according to you, can I compete? No, it is not possible.

This blindness to interdependence is not surprising. A variety of studies on the ability of entrepreneurs and managers to assess competition have found that people show limited ability to determine the relevant set of competitors (Camerer and Lovallo, 1999) and that they have a tendency to view only the most similar organizations as rivals (Porac and Thomas, 1994).

Furthermore, these behavioral factors may explain why some past studies have failed to find support for partitioning process in entry (e.g., Torres, 1995). In particular, near-center firms may crucially connect the behavior of center producers to the entry of producers distant from the center. Why should they matter? Because even if managers and nascent entrepreneurs maintain relatively restricted views of their competition, the existence of near-center producers means that at least some can exploit the positions that the center producers abandon. Hence, near-center producers might shift toward the center in response to increasing overlap among the center producers. Peripheral players, in turn, might observe the moves of these near-center producers and expand toward their abandoned positions, opening opportunities for peripheral entrants. The imagery becomes one of a vacancy chain (White, 1970), with each producer moving up to occupy the more central adjacent niche and simultaneously opening its past position for a somewhat more peripheral producer to occupy.

Finally, it is interesting to consider our results - and partitioning processes more generally-from the flip side. In other words, what does this theory say to the center 
producers that enact these processes? Can they prevent them? Although the emergence of large numbers of small competitors might seem more a nuisance than a real threat, in many industries those niche players have risen to challenge the center incumbents. Southwest and JetBlue come to mind in the airline industry, Nucor in steel. Center producers might do well to recognize that, by attacking and eliminating their large rivals, they may inadvertently clear the way for future pretenders to the throne.

\section{Acknowledgments}

We acknowledge the Swiss National Science Foundation (grant number: 112456) and the Spanish Ministry of Economics and Competition (grant number: ECO200908308) for financial support, Mediaset S.p.A. for providing data, and three anonymous reviewers for their comments on an earlier version of this paper. Any errors remain our own.

\section{References}

Barca, F. (2007), Le TV Invisibili. Storia ed Economia del Settore Televisivo Locale in Italia. Rai-Eri: Roma.

Barnett, W. P. and G. Carroll (1995), 'Modeling internal organizational change,' Annual Review of Sociology, 21, 217-236.

Blossfeld, H. P. and G. Rohwer (2002), Techniques of Event History Modeling. Lawrence Erlbaum Associates, Inc: Mahwah, NJ.

Bodo, C. and C. Spada (2004), Rapporto Sull'Economia Della Cultura in Italia 1990-2000. Il Mulino: Bologna.

Boone, C., G. R. Carroll and A. van Witteloostuijn (2002), 'Environmental resource distributions and the market partitioning of Dutch daily newspaper organizations,' American Sociological Review, 67, 408-431.

Camerer, C. and D. Lovallo (1999), 'Overconfidence and excess entry: an experimental approach,' American Economic Review, 89, 306-318.

Carroll, G. R. (1985), 'Concentration and specialization: dynamics of niche width in populations of organizations,' American Journal of Sociology, 90, 1262-1283.

Carroll, G. R. and M. T. Hannan (2000), The Demography of Corporations and Industries. Princeton University Press: Princeton, NJ.

Carroll, G. R., S. D. Dobrev and A. Swaminathan (2002), 'Organizational processes of resource partitioning,' Research in Organizational Behavior, 24, 1-40.

Carroll, G. R. and A. Swaminathan (2000), 'Why the microbrewery movement? Organizational dynamics of resource partitioning in the American brewing industry after Prohibition,' American Journal of Sociology, 106, 715-762. 
de Figueiredo, J. M. and B. S. Silverman (2007), 'Churn, baby, churn: Strategic dynamics among dominant and fringe firms in a segmented industry,' Management Science, 53, 632-650.

Demattè, C. and F. Perretti (2002), L’Impresa Televisiva. Etas: Milano.

Dobrev, S. D., T.-Y. Kim and M. T. Hannan (2001), 'Dynamics of niche width and resource partitioning,' American Journal of Sociology, 106, 1299-1337.

Dowell, G. (2006), 'Product line strategies of new entrants in established industries: Evidence from the U.S. bicycle industry,' Strategic Management Journal, 27, 959-979.

Freeman, J. and A. Lomi (1994), 'Resource partitioning and foundings of banking cooperatives in Italy,' in J. A. C. Baum and J. Singh (eds), The Evolutionary Dynamics of Organizations. Oxford University Press: New York, pp. 269-293.

Hannan, M. T., L. Pólos and G. R. Carroll (2007), Logics of Organization Theory: Audiences, Codes, and Ecologies. Princeton University Press: Princeton, NJ.

ISTAT (Istituto Nazionale di Statistica) (1999), Il Mercato degli Audiovisivi in Italia. Un'Analisi Strutturale per il Periodo 1980-96. ISTAT: Roma.

Kovács, B. and G. R. Carroll (2010), 'Niche width and scale in organizational competition: A computational approach,' Computational and Mathematical Organization Theory, 16, $29-60$.

McKendrick, D. G. (2001), 'Global strategy and population-level learning: the case of hard disk drives,' Strategic Management Journal, 22, 307-334.

Mezias, J. M. and S. J. Mezias (2000), 'Resource partitioning and the founding of specialist firms: the American feature film industry, 1912-1929,' Organization Science, 11, 306-322.

Owen, B. and S. Wildman (1992), Video Economics. Harvard University Press: Cambridge, MA.

Péli, G. and B. Nooteboom (1999), 'Market partitioning and the geometry of the resource space,' American Journal of Sociology, 104, 1132-1153.

Porac, J. F. and H. Thomas (1994), 'Cognitive categorization and subjective rivalry among retailers in a small city,' Journal of Applied Psychology, 79, 54-66.

Self, S. G. and K.-Y. Liang (1987), 'Asymptotic properties of maximum likelihood estimators and likelihood ratio tests under nonstandard conditions,' Journal of the American Statistical Association, 82, 605-610.

Sørensen, J. B. and O. Sorenson (2003), 'From conception to birth: Opportunity perception and resource mobilization in entrepreneurship,' in J.A.C. Baum and O. Sorenson (eds), Advances in Strategic Management. JAI Press: Greenwich, CT, pp. 89-117.

Sorenson, O. (2000), 'Letting the market work for you: an evolutionary perspective on market strategy,' Strategic Management Journal, 21, 577-592.

Soule, S. and B. G. King (2008), 'Competition and resource partitioning in three social movement industries,' American Journal of Sociology, 113, 1568-1610. 
Sutton, J. (1991), Sunk Costs and Market Structure. Cambridge, MA: MIT Press.

Swaminathan, A. (2001), 'Resource partitioning and the evolution of specialist organizations: the role of location and identity in the U.S. wine industry,' Academy of Management Journal, 44, 1169-1185.

Torres, J. C. (1995), The Dynamics of the U.K. Motor Industry: An Ecological Analysis. Unpublished dissertation, Stanford University.

Vermeulen, I. and J. Bruggeman (2001), 'The logic of organizational markets: thinking through resource partitioning theory,' Computational and Mathematical Organization Theory, 7, 87-111.

Wade, J. (1995), 'Dynamics of organizational communities and technological bandwagons: an empirical investigation of community evolution in the microprocessor market,' Strategic Management Journal, 16, 111-133.

Wagstaff, C. (2001), 'The media,' in Z.G. Baranski and R.J. West (eds), Modern Italian Culture. Cambridge University Press: Cambridge, pp. 293-309.

White, H. C. (1970), Chains of Opportunity: System Models of Mobility in Organizations. Harvard University Press: Cambridge, MA. 